\title{
LOS PAISAJES DEL AGUA: NATURALEZA E IDENTIDAD EN LA CUENCA DEL RÍO VALDIVIA
}

\author{
LANDSCAPES OF WATER: NATURE AND IDENTITY \\ IN THE VALDIVIA WATERSHED
}

\author{
Juan Carlos Skewes ${ }^{1}$, María Eugenia Solari ${ }^{2}$, Debbie Guerra ${ }^{3}$ y Daniela Jalabert ${ }^{4}$
}

\begin{abstract}
Las identidades colectivas se adecuan al diseño que las poblaciones imponen al paisaje. El estudio de las comunidades de la cuenca norte del río Valdivia y su acomodo a los cursos y manifestaciones del agua permite explorar las estructuras subyacentes a sus identidades, estructuras que revelan la impronta del paisaje en las prácticas sociales. En la historia de estas comunidades, incluyendo momentos críticos como la constitución de la propiedad (1904-1960), el Complejo Maderero de Panguipulli (1970-1973) y la generación hidroeléctrica (2009 en adelante), la referencia al agua es inescapable. En el análisis de esta historia se distinguen, a modo de tipos ideales, dos modelos de organizar el paisaje que condicionan de modo diverso las actuales identidades chilena y mapuche. Uno es el modelo dendrítico, característico de la adaptación de la cultura mapuche al comportamiento de las aguas; el otro es el reticular, que da cuenta del sometimiento de las aguas al imperio de una racionalidad foránea. Ambos modelos enmarcan la percepción y autopercepción de las poblaciones locales, influyendo así las formas de identidad colectiva vigentes en las prácticas de los actuales residentes de la cuenca.
\end{abstract}

Palabras claves: paisaje, cuenca del río Valdivia, modelos dendrítico/reticular, Mapuche.

Collective identities adapt to the design that populations impose on their landscape. The study of the communities of the northern basin of the Valdivia river and their adaptation to the lines and bodies of water allows one to explore the underlying structures of their collective identities, structures that reveal the imprint of the landscape upon social practice. In the history of these communities, including such critical moments as the constitution of property (1904-1960), the Timber Industrial Complex of Panguipulli (1970-1973) and hydroelectric projects (from 2009 onwards), references to water are inescapable. The analysis of this history, two idealized models of organizing landscape are revealed, each conditioning in different ways the construction of identity in both Chilean and Mapuche communities. One is dendritic, characteristic of the Mapuche adaptation to the movement of water; the other is reticular, expressing the control over water by a foreign rationality. Both models frame perception and self-perception among local populations, influencing current collective identities evidenced in the social practices of the basin's residents.

Key words: Landscape, Río Valdivia basin, dendritic/reticular models, Mapuche.

El comportamiento histórico y actual de las comunidades de la cuenca norte del río Valdivia pone de relieve que la tensión que diferencia a los actores en el acceso, uso, significado y control de las aguas, es la oposición entre el acomodo al comportamiento de los cuerpos hídricos y su contención. La presencia chilena transforma la cuenca, sometiéndola a coordenadas definidas desde un sistema metropolitano, mientras que el universo indígena se enmarca en las referencias que el paisaje local proporciona. Esta oposición se expresa en las prácticas productivas y en las representaciones simbólicas a través de las que se autoidentifican las poblaciones chilena y mapuche y que condicionan sus interacciones, contribuyendo a mantener las diferencias identitarias que las separan a lo largo de los siglos XX y XXI. Las prácticas sociales traducen esta dicotomía en la construcción de mundos diferenciados por la relación establecida con la naturaleza.

La imbricación espacial de los grupos sociales juega un papel estructurador en la definición de sus identidades colectivas como estado compartido de conciencia asociado al sentimiento de pertenecer a una categoría de personas (Barrera 2000). Estas identidades se articulan en distintos niveles y pueden

1 Departamento de Antropología, Universidad Alberto Hurtado, Santiago, Chile. jskewes@uahurtado.cl

2 Laboratorio de Arqueobotánica e Historia Ambiental, Instituto de Ciencias Sociales, Universidad Austral de Chile, Valdivia, Chile.msolari@uach.cl

3 Centro de Estudios Ambientales, Instituto de Enfermería Materna, Universidad Austral de Chile, Valdivia, Chile. dguerra@uach.cl

4 Escuela de Antropología, Universidad Austral de Chile, Valdivia, Chile.da_ji_86@ hotmail.com 
adquirir un carácter imperativo y excluyente, como la etnicidad. La intensidad de estas identidades se asocia con los aspectos garantes de la existencia del grupo siendo las vinculaciones territoriales percibidas en tal condición.

Las identidades colectivas se moldean de acuerdo a las prácticas espaciales imbricadas en las experiencias paisajísticas. Las aguas, rasgo prominente de la naturaleza local, adquieren un carácter estratégico para que las comunidades se constituyan, simbolicen y se piensen en sus relaciones recíprocas. Es lo que hemos podido relevar en la exploración realizada en la cuenca norte del río Valdivia (zona cordillerana de Panguipulli y Neltume y microcuenca del río Leufucade en la comuna de Lanco [Figura 1]. El trabajo etnográfico (2009-2011) se ha focalizado en territorios cuya historicidad está marcada por la contradicción entre una población chilena que se expande a lo largo del siglo XX y la población mapuche que se repliega hacia tierras de refugio en las zonas montañosas, donde sus patrones de asentamiento logran conservarse, a pesar de estar inmersos en un escenario dominado por la actividad maderera. El modelo de ocupación impuesto por el colono se implanta junto a los cuerpos y cursos de agua principales, con el propósito de conectar el área con la región y la metrópoli.

Las áreas consideradas para el estudio son los asentamientos de Panguipulli, Neltume y Malalhue, en cuanto paradigmáticos de la ocupación chilena y las comunidades aledañas a los lagos Neltume, Panguipulli y Calafquén y la comunidad de Huillimallín, próxima a Malalhue, en tanto representativas de la población mapuche. La estrategia metodológica se apoya en el análisis del material histórico referido a los procesos de colonización del interior de la provincia de Valdivia, principalmente los informes de los inspectores de colonización, protectores de indígenas y decretos y disposiciones legales a través de los que se ordena el territorio. La información documental complementa las rondas etnográficas realizadas en el territorio, las que constituyen una estrategia de investigación que permite el desplazamiento del equipo investigador durante el ciclo anual y el uso de técnicas diversas, incluyendo la observación, junto con estimular a la comunidad local, a través de un grupo interlocutor, para reflexionar acerca de las identidades y paisajes de que son parte. Los resultados que se obtienen retroalimentan la reflexión junto a la comunidad.
Estas exploraciones han permitido discernir la existencia de los modelos de acomodo y control que caracterizan la relación de las comunidades locales con los cursos y cuerpos de agua a nivel de la cosmovisión, de la vida ritual, y de las prácticas técnicas e instrumentales, aquí descritos como dendríticos y reticulares. En el primer caso, se usa la morfología neuronal en un sentido figurado para describir una formación social que se extiende a partir de núcleos originales de poblamiento, prolongaciones sensibles a los cambios ambientales y que permiten provocar el desarrollo de otros núcleos. Las dendritas son numerosas, ramificadas, difusas, fibrosas y de contornos imprecisos y geográficamente corresponden a la adecuación de la población al territorio sobre la base de una geometría irregular (Lindsay et al. 2001). Las retículas, en cambio, encarnan territorialmente formas geométricas regulares que devienen de la acción planificadora que acompaña al poblamiento (Whiteaker et al. 2006). La retícula construye un mundo para ser habitado y su hegemonía plena se da en la modernidad, donde la línea recta establece su precedencia, emergiendo como su ícono virtual e "índice del triunfo del diseño racional y propositivo por sobre las vicisitudes del mundo natural" (Ingold 2007:152, traducción nuestra). Semejante hegemonía, como se evidencia en lo que sigue, no es el fruto del convencimiento procurado por la razón tanto como de la reorganización del mundo por la vía de la fuerza.

Estos modelos, a la manera de los regímenes de naturaleza, son campos de articulación entre lo biofísico y lo social, se co-constituyen relacionalmente, reafirmando recursivamente su unidad (Escobar 1999). Se distinguen por ser principios ordenadores y no sólo productos: las coordenadas que organizan el territorio desaparecen al cobrar vida las entidades por ellas creadas, como ocurre con los mapas que dan la impresión de derivar su estructura de la estructura del mundo (de Certeau 1984).

La distinción entre dendritas y retículas se subjetiva en la memoria e identidad de las comunidades sujetas a una u otra modalidad paisajística: se postula que en el caso de las dendritas, las identidades se arraigan en las características de la geografía local mientras que, en el caso de los paisajes reticulares, las identidades locales reproducen y se subordinan a las coordenadas metropolitanas de las que dependen. En este caso, el territorio se ordena de acuerdo a una racionalidad que le es ajena, definida por un conjunto de hitos y líneas que dan cuenta de formas 


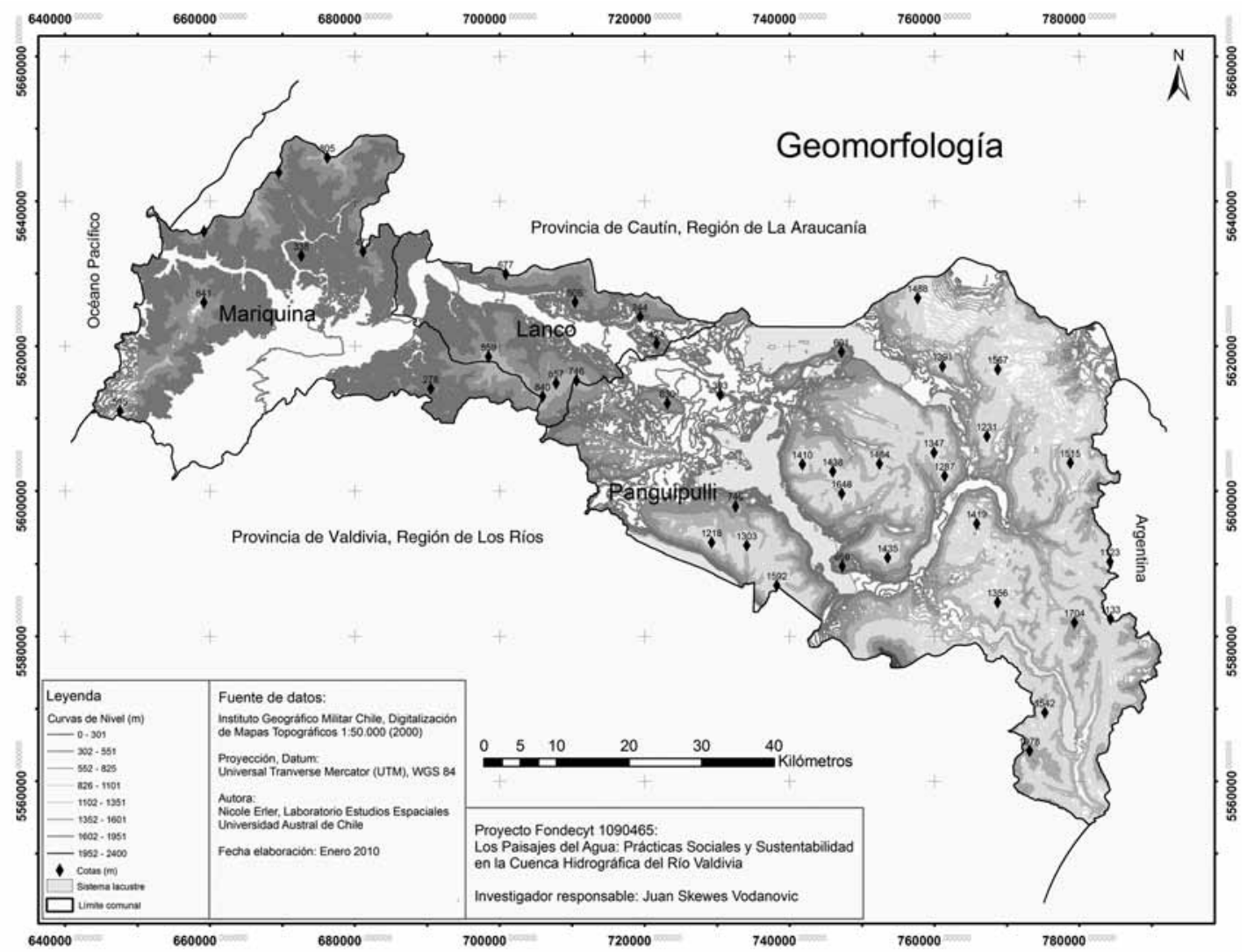

Figura 1. La cuenca norte del río Valdivia (elaboración propia).

The northern basin of the Valdivia river (authors' image).

jerarquizadas de ramificación desde los centros metropolitanos hacia las periferias. En el otro, las identidades se arraigan en las características de la geografía local, constituyéndose con niveles de relativa autonomía.

\section{Identidades Dendríticas y Paisajes del Agua}

La observación y análisis del acomodo de las poblaciones a los cursos y cuerpos de agua y sus implicancias en las prácticas rituales y en la cosmovisión permiten incorporar una nueva dimensión a la comprensión de los procesos identitarios: el componente material que sirve de soporte a la memoria colectiva. Este componente se ancla en la vida cotidiana a través del paisaje y de su diseño, impregnando la subjetividad de la persona y del grupo (Strang 2006). Frente al excesivo énfasis puesto por la literatura en el carácter construido, arbitrario y efímero de la identidad, esta perspectiva constituye un antídoto. Aquí se retoman las dimensiones sustantivas de las identidades colectivas, esto es, patrones específicos que organizan la experiencia histórico material de una colectividad para definir un trasfondo inescapable para su autoidentificación (Strang 2006). La diferencia en relación a los otros se constituye sobre bases percibidas como fundantes de la comunidad, tales como el parentesco, el territorio y, muy especialmente, la historicidad conflictiva a que las poblaciones se hayan enfrentado (Connors 1994). Desde una perspectiva ecológica tal historicidad se inscribe en el paisaje, donde se articulan la historia y la biología mediadas por la cultura (Escobar 1999; Latour 1999). Tal articulación se vuelve estratégica al definirse la identidad del grupo. Al discurso público y las prácticas cotidianas propuestas por Larraín (2003) cabe, pues, agregar la dimensión material en la constitución de las identidades y de los paisajes.

El concepto de paisaje proporciona una valiosa perspectiva, puesto que permite abordar las transformaciones, creaciones y percepciones de la 
naturaleza, considerando las dimensiones material e inmaterial, y la posibilidad de acoger aspectos discursivos y emocionales que intervienen en su modelado (Lipietz 2002; Hirsch y O'Hanlon 1995; Sauer 1925; Sellin 1996; Villagrán et al. 2000). A través del paisaje se produce la lugarización del mundo, esto es, la construcción de un significado particular de la biósfera a partir de la experiencia histórica de un grupo humano (Criado 1999; Lawrence-Zuñiga 1996; Tuan 1974; Zedeno et al. 1997). Los paisajes pueden ser interrogados desde cuatro miradas: (i) Histórica: ¿Cómo llegaron a ser lo que son?, (ii) Cultural: ¿Qué significan para quiénes?, (iii) Político: ¿Quiénes quieren darles qué forma?, y (iv) Crítico: ¿Podrían ser de otro modo? Estas interrogantes permiten acompañar la lectura de los procesos que vinculan a las comunidades locales con sus paisajes.

\section{Dendritas y Retículas en la Cuenca del Río Valdivia}

El agua es una de las dimensiones ineludibles en la constitución de los paisajes y en la existencia social de los grupos que los habitan, es un elemento que gravita decisivamente en la existencia social de cualquier grupo humano, tanto en la dimensión material como inmaterial, y en torno suyo se definen las modalidades para su acceso, distribución y disposición, y sus significaciones y valores (González 2007). Su naturaleza fluida y cambiante se asocia a los elementos más permanentes del paisaje (como el relieve y las rocas), a los que, a su vez, conecta (Strang 2006). Este carácter otorga al agua un valor especialmente significativo como símbolo natural (Douglas 1988) y su fluidez invita a concebir, análogamente, la identidad humana "como un proceso cambiante que se conforma en relación a las características del ambiente inmediato cuya transformación es, por lo general, más lenta" (Strang 2006:218, traducción nuestra).

En el contexto del área de estudio, el agua aparece con un valor estratégico tanto en la organización del territorio como en la cultura local. Para Latcham (1924), entre los mapuche el agua (co), se refiere a las aguas lluvias, vertientes y pequeños riachuelos formados por ellas y también a causa de los temporales. Entre las distintas formas del agua se reconocen los witrunko o witrukonpun (chorros o corrientes de agua de esteros cuyas agua puras invitan a la realización del wetripantu), los liloco (aguas nacientes de las rocas), los kayenko (aguas que contienen abundantes piedras), los metrenco (agua sucia o con troncos), y los cuyinco (aguas arenosas). Las superficies planas (laf) llenas de agua forman mares y lagos (lafken) (Pirihueico, Panguipulli, Neltume, Calafquén, entre otros) y las aguas en movimiento dan lugar a los leufu o ríos (como Fui, Leufucade, Cruces, o Valdivia). También están las aguas subterráneas que afloran en los menocos (pequeñas lagunas de lodo), que se acumulan en mallines (pantanos) y hualves (humedales), y que persisten como catricos (o ríos subterráneos) (ver de Augusta 1995 [1916]; Wilhelm de Moesbach et al. 1993). Las pire (o nieves) de los macizos cordilleranos, las mawün (o lluvias), las tromü (o nubes), las trayen (o cascadas), los relmu (o arcoíris) completan el paisaje constituido en la cuenca, cuyas aguas han regulado históricamente la relación entre sus habitantes indígenas y no indígenas.

Los dos cursos principales de la cuenca han sido escenario de eventos geológicos y de cambios climáticos que se traducen en aluviones, inundaciones y sequías, cuyo impacto en la sociedad local deja huellas que las generaciones conservan en su memoria y encarnan en sus prácticas. Hacia fines del siglo XIX y a lo largo del XX el área es objeto de la expansión chilena, ocupando las actividades agropecuarias e industriales la depresión intermedia y la actividad forestal el interior, principalmente Panguipulli (Camus y Solari 2008) (Figura 2).

La superficie correspondiente a las actuales comunas de Lanco y Panguipulli es impactada por la expansión maderera y la búsqueda del oro, expansión asentada junto a los cursos fluviales y zonas lacustres. La empresa Camino i Lacoste inicia la penetración el año 1898 y su actividad se complementa con la de la Compañía Ganadera San Martín, la cual trae el vapor O'Higgins para el transporte lacustre en el lago Panguipulli (Rehren 1908; Rivas 2006). La expansión se materializa en la explotación de los bosques y en la fundación de centros poblados y con la actividad misional de los padres Capuchinos, cuya escuela de Panguipulli se crea en 1904 (Alarcón 1958).

Fruto de este proceso hay un reacomodo espacial que gravita hasta nuestros días y cuyas materialidades delimitan los campos identitarios mapuche y chileno, configurando dos modalidades de asentamiento basadas en las formas de acceso y control de las agua. En el caso indígena, la retracción hacia el interior se hace en referencia a las vertientes y 


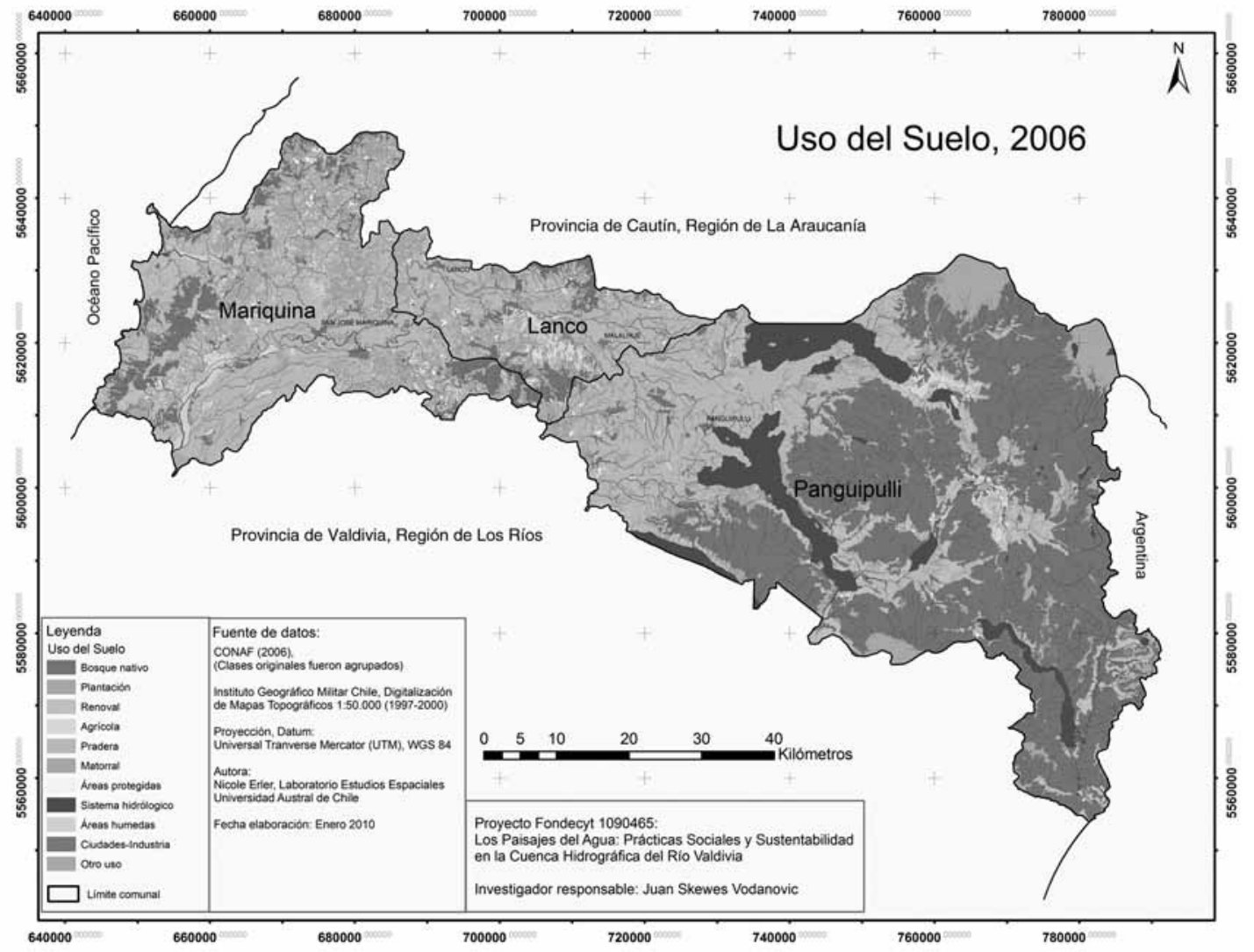

Figura 2. Usos del suelo: Lanco y Panguipulli (elaboración propia).

Land use: Lanco and Panguipulli (authors' image).

esteros que permiten sostener actividades orientadas al autoconsumo, combinadas con prestaciones para el transporte de madera (yuntas de bueyes) y venta de fuerza de trabajo a las empresas forestales. En el caso chileno, el poblamiento se basa en el control sobre los principales cuerpos y cursos de agua, a los que se asocian las rutas terrestres, fluviales y lacustres. La etimología de las voces Neltume y Malalhue ilustra esta distinción: en mapudugun, el vocablo neltun significa dejar libre y men la acción de ir hacia allá: la palabra alude al ir hacia la libertad (Rivas 2006; Triviños 1959). Malalhue, en cambio, se traduce como lugar cercado (de Augusta 1995 [1916]:139). El contraste distingue las formas de vinculación al paisaje que caracterizan a una población y a otra.

La fundación del poblado chileno en Malalhue, por ejemplo, significó la reubicación de la población mapuche, no obstante el avance colonizador se apoya en el trabajo indígena: el puente sobre el rio Leufucade "lo hicieron mapuche a pura pala". La conectividad vigoriza el proyecto chilenizador, estableciendo fronteras. "Para venir al colegio", recuerda uno de los residentes mapuche de Huillimallín, "teníamos que cruzar ese puente". La chilenización fue la "despatriación" de los mapuche: "Mi bisabuela se fue para arriba. Llegó una comisión de gente con más educación. Los que estaban en Huillimallín se fueron, todos despatriados los mapuches". Las identidades se redefinen y el estero separa los dos mundos. "El Huillimallín era una frontera para el pueblo y para la comunidad indígena", recuerda un vecino chileno. "Quien cruzara al otro lado del estero, pasando por el pozo, iba a otra parte, a un mundo diferente", prosigue. "Era cruzar a otro mundo".

\section{i. La dendrita}

En las tierras marginales del territorio cordillerano la memoria e identidad local están contenidas en las formas que adopta el asentamiento, en sus 
prácticas sociales y rituales y, sobre todo, en el paisaje del que son parte. Las comunidades se ubican junto a los esteros, en las laderas de cerros cuya accidentada topografía los tornan inviables para la penetración chilena (Figura 3). "Ahí tenían (sus tierras) los Aillapán, los Nahueles, los Curiñanco, los Curinao", informa un colono chileno. Estos asentamientos importan una conexión simbiótica con el paisaje, fundada en la verticalidad que explica el origen de los lagos, montes y ríos, en tanto fuentes de la vida. El lago, según describe un lonko de la comunidad local, concentra en sus aguas una gran cantidad de energía traída por los diversos cursos aguas. El lago Neltume congrega a diversos espíritus, tiene vida y "tiene vida porque si no se secaría, así no más no nació, hay alguien que lo anima".

En las comunidades mapuche queda de manifiesto la formación dendrítica que se integra al paisaje a través de la verticalidad que domina la vida cotidiana y ritual. Los humanos nacen de la tierra y se ordenan según las aguas: su incorporación al paisaje está en

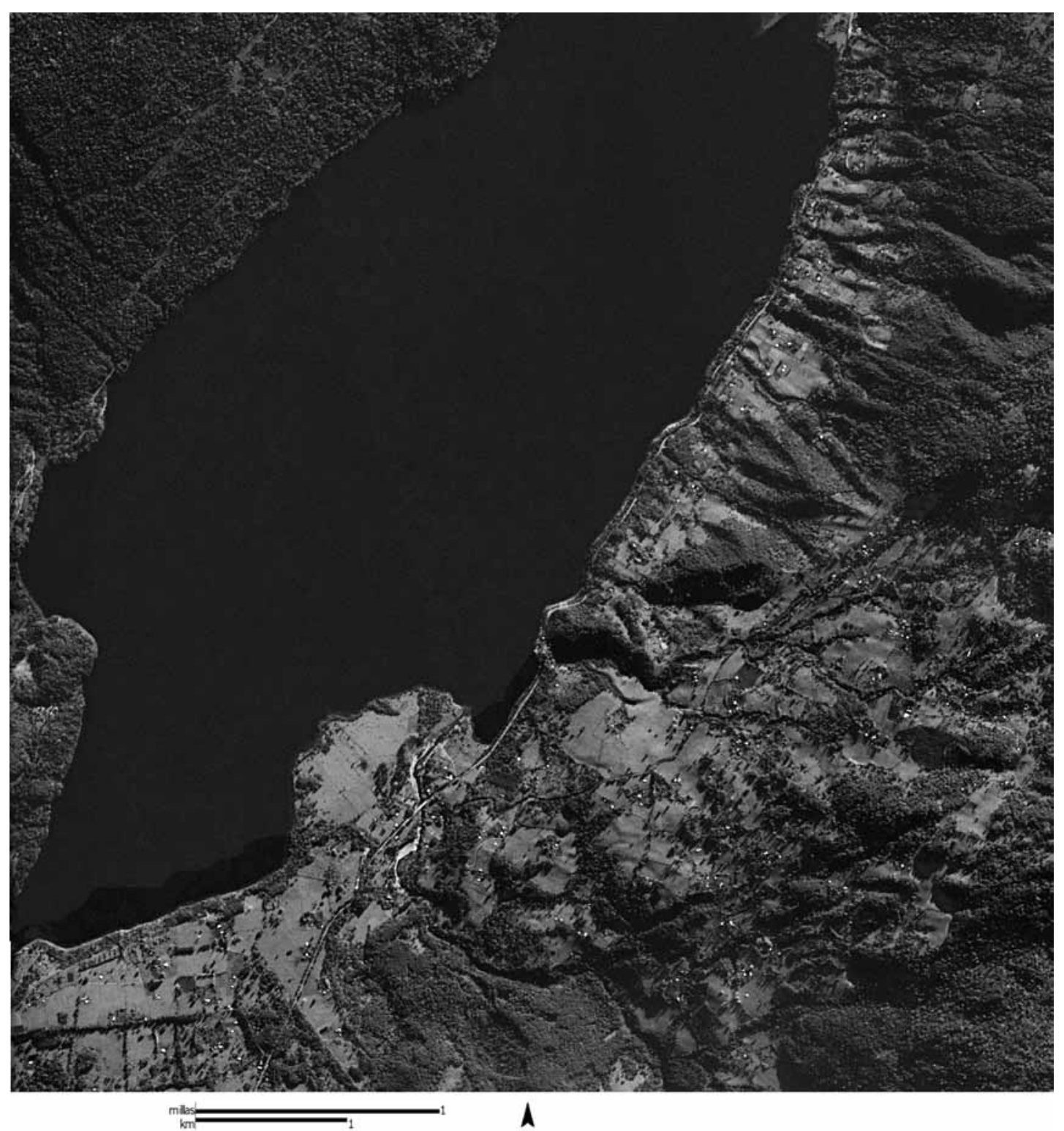

Figura 3. La dendrita en el lago Neltume (adaptado de Google Earth)

The dendritic pattern in Neltume lake water (adapted from Google Earth). 
cierto modo preanunciada. El parentesco se inscribe en el paisaje. Las casas se ordenan tomando como referencia las quebradas y cursos de agua que se asocian con las distintas líneas familiares, dejando a la vista el volcán y el lago. En la imagen de un lago vivo, habitado por una multiplicidad de seres, se encuentra la raíz identitaria de una población cuyas familias bajan desde los cerros, al igual que las aguas, a celebrar en tiempos de nguillatwe (la rogativa mapuche comunitaria) o a entregar a sus difuntos a la comunidad en los descansos (ritual ejecutado en las inmediaciones del predio familiar donde se entrega el ataúd -antiguamente era la canoa mortuoria, wampo- a la comunidad que lo llevará hasta el cementerio) en su última detención antes de la partida.

El nguillatwe articula los componentes paisajísticos principales -el volcán, los cursos de agua, la pendiente y el lago- incorporándolos en forma decisiva a la vida ritual para hacer confluir los múltiples espíritus del territorio tanto con el espacio de reunión de las autoridades tradicionales, bajo la protección de un pellín (Nothofagus obliqua) y como con el campo sagrado dentro del lago, en la porción de tierra que se descubre en los meses estivales. Caen dentro de este eje el cementerio y algunos descansos. El motivo de la celebración es el agradecimiento a ngen chao por la fertilidad de la tierra y la salud de sus habitantes, e incluye el sacrificio ritual de un toro -cuyo color es el del volcán- que se ofrenda a las aguas del lago. Chumpalwe o el Dios del lago autoriza la celebración. "Venimos a saludar el lago, le venimos a decir que mañana vamos a estar aquí, que nos espere. En el cementerio invitamos a los bisabuelos, a los espíritus que están ahí. Les avisamos que ellos vengan para acá al lago y acá venimos a decir que nos espere. Así que nos ganamos todos a la orilla y tenemos que estar pendientes de todo, no estar mirando para el otro lado, porque no todos tienen la posibilidad de ver, tiene que pasar un salmón, muy cerca tuyo. Pasa en el momento en que estamos acá, avisando que vamos a venir. Pasa siempre, pero no todos tienen la posibilidad de verlo, puede estar ahí mismo pero no lo ven. Hay que tirar el mudai al lago y aparece el salmón, pasa de aquí para allá por la orilla. La idea es que siempre tiene que llegar al mudai, siempre. Al otro día está calmo el lago". Nunca se ha hecho nguillatwe sin el consentimiento así obtenido: no en vano, el lugar escogido coincide con las zonas de movimiento de los peces que habitan el lago (Figura 4).
El agua es objeto de reverencia (Foerster 1995; Skewes y Silva 2007). En el nguillatwe "nadie coloca sus manos en el agua, para ese día es sagrado. Porque o si no se empieza a nublar y el lago empieza con viento, se empiezan a formar olas. Pero si uno no hace nada, el lago permanece tal cual, tranquilito", dice uno de los participantes de la ceremonia. Al lago se tranquiliza con mudai. Bajo sus aguas se conservan los animales sacrificados y espíritus que, como "cueros", dan vida a un espacio numinoso y temido: pocos son las o los comuneros que se sumergirían en sus aguas, las que lo unen al volcán. "Donde vaya hay agua caliente, hay minerales", describe una de las mujeres antiguas del territorio. "Hay agua caliente, en esta tierra, por debajo, a donde vaya". El mundo está marcado por las venas del volcán.

En lo cotidiano, el agua marca la existencia social. El comportamiento es dendrítico al adecuarse las comunidades a los rumbos de las aguas. La exposición a éstas es permanente pero hay un aprendizaje que permite establecer una relación de convivencia. "Siempre estamos húmedos, nunca dejamos de estar con esta humedad en vela, cuando llueve tres, cuatro días, el agua está a flor de tierra y cuando llueva cinco días nosotros no podemos salir", asegura una vecina del sector de Huillimallín $\mathrm{y}$, sin embargo, "a ni una casa le ha entrado agua adentro, a pesar de que corre con mucha corriente. Toda agua respeta la casa. Yo, al momento de elegir mi casa, llegué y mi madre miró todo el campo, y me dijo: "Aquí, hija, no te va a entrar agua a la casa nunca". Hubo hace dos años atrás una subida de agua muy grande. Yo lloré, el agua llegó al portón de mi casa por atrás y al portón por delante, siempre mantuvo su distancia, siempre respetó mi espacio y así pasa por cada una de las casas".

La identidad se configura merced del carácter dendrítico del paisaje, pero no se expresa tanto en el verbo como en las prácticas y, entre ellas, la que mayor compromiso identitario importa es la celebración de la rogativa que sella la participación del sujeto con el colectivo del que es parte. Tales obligaciones establecen el círculo de las reciprocidades y, en la profundidad de la conciencia, la naturaleza del ser humano.

\section{ii. La retícula}

La dendrita deja de serlo cuando se aplica el modelo geométrico. La resistencia que las 


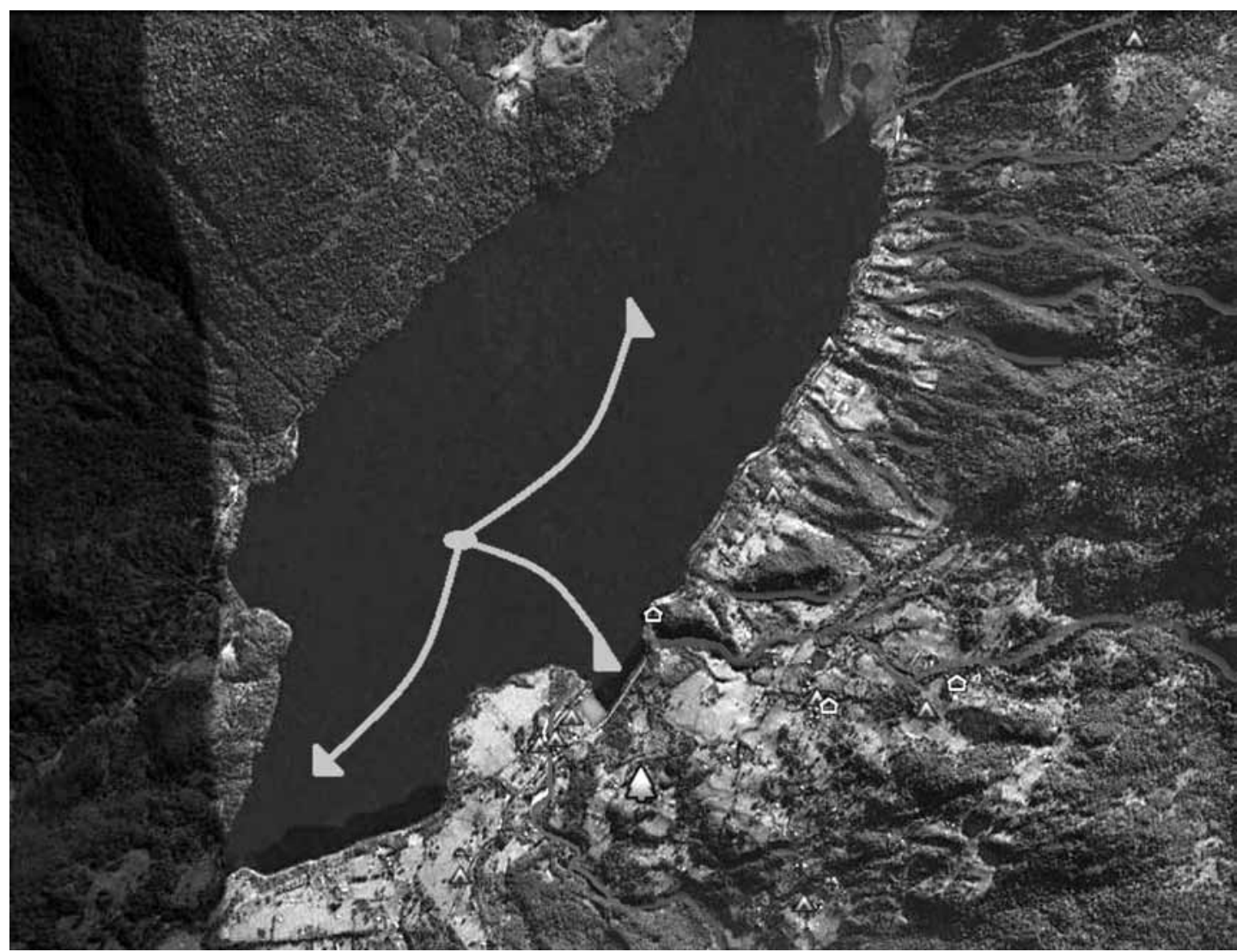

Figura 4. Desplazamiento de los peces en el lago Neltume (adaptado de Endesa 2010).

Movement of fish in Neltume lake (adapted from Endesa 2010).

comunidades mapuche expresan frente a la radicación testimonia la contracción que para ellas estos trazados suponen: "Rechazan las leyes vijentes porque ellas les obligan a radicarse i porque con esta operación se les limita la cabida de sus posesiones a un pequeño número de hectáreas" (Irribarra 1909:353). "No seamos egoístas", prosigue el Protector de Indíjenas (Irribarra 1909:359), "miremos las cosas con más humanidad. Dejemos a los naturales con esas pequeñas exigencias ... dejémosles vivir que también tienen derecho a la existencia, dejémosles en sus rucas, allá en el rincón del bosque, hasta que el torbellino de la civilización les confunda con sus victimarios civilizados".

A fin de consolidar el proyecto de integración territorial y de conectividad se promueve la formación de núcleos residenciales para la colonización, la instalación de misiones capuchinas y la regularización de tierras con la entrega de títulos de merced a las comunidades indígenas. El proyecto involucra un ordenamiento territorial que a poco andar es traicionado por sus agentes, pero no por ello deja de imponer los contornos de una geometría rectilínea. El Inspector General de Colonización, Otto Rehren (1908), se muestra decepcionado del avance del proyecto colonizador. El Estado ha subsidiado a empresas como Lacoste i Camino para poblar el nиеvo territorio; la empresa, sin embargo, se ha apropiado del extenso territorio sin poblarlo, según estaba previsto, iniciando el despliegue de la gran propiedad maderera. Los que pudieron haber sido pueblos se convierten en poblaciones obreras, estableciéndose el modelo reticular como patrón de concentración demográfica. Un antiguo residente de Panguipulli cuenta que "cuando llegaron los fundos -cuando llegó esta gente grande-empezaron a tomar, a comprar a lo mejor un pedacito y se hicieron cargo de ahí y después se fueron extendiendo para allá y a los indígenas los fueron echando más al rincón".

En paralelo se desarrolla la actividad vial y de transporte. La concesión otorgada a la Compañía Ganadera San Martín para "la navegación de los 
ríos que unen los lagos" impone las siguientes condiciones: dragado y limpia de los cursos de agua, la construcción de una aduana, la habilitación de caminos terrestres y rebaja del pasaje al funcionario público en comisión de servicio (Ministerio de Hacienda 1906). Con la llegada de la Compañía, la libertad en el uso de las aguas se restringe para beneficiar al O'Higgins con el transporte exclusivo de carga y pasajeros. El vapor, amparado por la fuerza de la ley, desplaza a la canoa. "A los pocos días de estar en servicio ..., se hizo saber a los indios que era absolutamente prohibida la navegación del lago en canoas sin permiso de la Compañía. Al efecto el capitán del vapor tenía orden de apresar y de destruir toda embarcación que sorprendiera en flote" (Díaz 2005[1907]: 152). Con su funcionamiento se establece una ruta lacustre que incorpora paradas, horarios y valor de un pasaje que hasta ese entonces era desconocido, demarcándose así la línea de tránsito entre Panguipulli y Choshuenco. Con este sistema de transporte, la población mapuche no pudo hacer uso de sus canoas, viéndose obligada a caminar grandes distancias ante la imposibilidad de costear el pasaje. Las líneas de navegación pueden en rigor considerarse las retículas dibujadas sobre el agua.

La semiología del paisaje cambia a partir del control del agua. Los esteros truecan su vitalismo en pro de su uso instrumental como recurso amoldable según las necesidades de la población urbana. Constantemente estos cursos fueron desviados. En el caso del estero Ancacomoe, recuerda un antiguo colono, "no pasaba por el centro aquí de Panguipulli, sino que cortaba al lado de arriba e iba a salir al lado de allá del muelle". Sin embargo, su curso fue alterado para servir un molino de un próspero colono. Los esteros fueron parte fundamental de la geografía colonizadora y por su acotada dimensión se pudieron intervenir, desviar o rellenar según las necesidades del momento.

La inspiración reticular pugna por atravesar el territorio, según recuerda uno de los colonos de Panguipulli. Hacia 1920, para entrar y salir de Panguipulli, había que dirigirse hacia la ribera sur del lago. Se salía a lomo de caballo y mula ("porque las mulas eran las camionetas para llevar las cargas") rumbo a Riñihue. Sólo se podía galopar en las pampas de Ñancul "y después era un caminito angosto a caballo, a caballo hasta llegar a Riñihue". Allí estaba el barco Enco, "que se llamaba Riñihue en ese tiempo". En ese puerto terminaba la línea del tren construida por la Sociedad Comercial y Ganadera General San Martín, que por problemas económicos nunca alcanzó a su destino, San Martín de los Andes, en Argentina (Bernedo 1997). Finalmente se llegaba a Los Lagos para tomar el tren que une a Santiago con Puerto Montt.

Las referencias se desplazan desde los hitos naturales (volcán, lago, estero) a los urbanos (calles, fundos, instituciones). El diseño territorial se articula en la subjetividad de los colonos quienes reproducen la divisoria mental que les separa del mundo de "los naturales y de la naturaleza". Una nueva identidad se incuba en la cordillera a la que concurre tempranamente el pueblo de Neltume. Allí, en 1898, se había emplazado el primer banco aserradero de la empresa Camino, Lacoste i Compañía (Rivas 2006) y en las décadas siguientes se instalan las fábricas en Panguipulli. Los aserraderos se constituirán en el sello industrial identitario de la región cordillerana.

La geografía local cede ante la rigidez que le es impuesta. La construcción del camino LancoPanguipulli es considerado por la Municipalidad de Lanco como "el más importante de la provincia de Valdivia" (Diario Oficial 1931). El proyecto vial es adjudicado en agosto de 1932 y se justifica en función de su potencial turístico, agrícola y maderero "que por las dificultades de acceso es difícil de explotar" (Dirección General de Obras Públicas 1932). La Sociedad Agrícola y Maderera Neltume Limitada crea, en la década siguiente, la Fábrica de Terciados y la Industria de Maderas Sociedad Anónima (IMASA) para elaborar puertas y ventanas. En torno al lago Panguipulli se consolidan los fundos Toledo, Puñir, Releco, Chan Chan, Quechumalal, Enco y Choshuenco, para los que la presencia lacustre favorece su desarrollo en comparación a Neltume. Usaban botes, lanchas y lanchones para mover sus productos. "Ellos se dedicaban a aserriar no más", comenta otro vecino de Neltume.

Las nuevas empresas (Echavarri y Bravo, Releco, Forestal Trafún, Compañía Pirehueico y Sociedad Carranco) atraen mano de obra (Rivas 2006). El lago es surcado día y noche por embarcaciones y lanchones cargados con maderas que eran encastilladas en el puerto de Panguipulli para ser comercializadas en el país. "El uso más grande que le dieron al lago (fue) la navegación. Como no existía el camino por la ribera norte del lago ... acá llegaron a haber como diecinueve embarcaciones entre remolcadores, buques de pasajes", señala un residente de Choshuenco. 
En 1943, la creación de la comuna de Panguipulli confiere fuerza legal a la geografía que se ha impuesto al territorio. La necesidad de precisar sus contornos responde al precario conocimiento que se tenía antes del territorio. Los límites de Panguipulli se establecen en función de ríos, lagos y esteros de propiedades mayoritariamente representadas por fundos de colonizadores (Diario Oficial 1931).
Son estos los contornos de la retícula: de ser nodos habitacionales se van configurando como rutas y fronteras, enclavando el poblamiento según los intereses comerciales (Figura 5).

La retícula se fortalece con la creación del Complejo Forestal y Maderero Panguipulli, en 1970, e indiferente a los giros ideológicos, también se beneficia con las iniciativas surgidas con

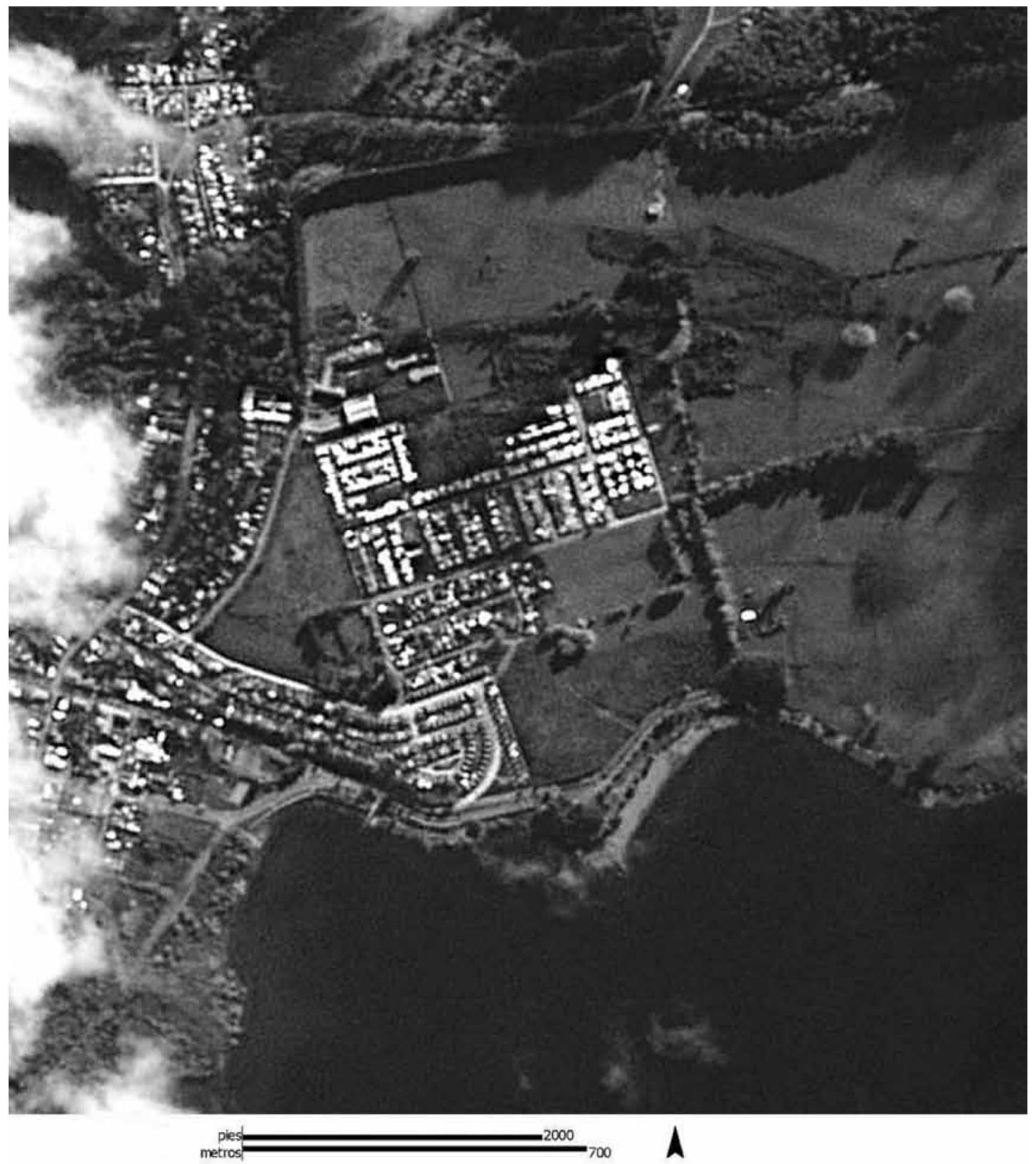

Figura 5. La retícula en Panguipulli (adaptado de Google Earth).

The grid in Panguipulli (adapted from Google Earth). 
la internacionalización de la economía. La movilización social generada en la lucha por la tierra motiva la expropiación de los fundos madereros y su organización bajo la forma de un modelo industrial que viene a ser la culminación y el fin del proceso que se iniciara tímidamente en Neltume. Según recuerda un testigo del Complejo Maderero, éste concentraba la población en construcciones aledañas al aserradero (donde se ubicaba la sierra echona), al tanto que "en los cerros se usaba el aserradero de montaña y el locomóvil para instalar campamentos de rukos". El modelo refuerza el asentamiento articulado con los centros urbanos e integrado a cadenas de producción extralocales (por lo que no llama la atención el hecho que se produjeran conflictos con las comunidades indígenas vecinas al Complejo) (Guerra et al. 1999; Rivas 2006).

El cierre del Complejo y su posterior desmantelamiento marcan el decaimiento de la actividad forestal y maderera y las obras viales -principalmente la construcción del camino de Panguipulli a Choshuenco- ponen fin al constante flujo de lanchones con maderas y la ruta diaria del vapor Enco. No obstante, desde el punto de vista de la organización reticular del territorio, se inauguran nuevas modalidades de someter a los cuerpos de aguas a la actividad humana movilizada por intereses extralocales.

Con la economía neoliberal, la retícula se pone al servicio de actividades globales: el turismo, la agricultura de exportación y la generación eléctrica. El paisaje de la cuenca se ofrece al turista y, a través de fondos concursables, el Servicio Nacional de Turismo (SERNATUR) especializa a una parte de la población para atender su demanda: nace el "Destino Siete Lagos", que destaca la naturaleza milenaria, la flora y la fauna del lugar, ofreciendo servicio de hostales, expediciones, restaurantes y actividades recreativas asociadas a una identidad local folclorizada. Las aguas adquieren un valor escénico que las desarraiga de los tejidos sociales a los que habían dado vida. Se produce un progresivo distanciamiento entre las propiedades del interior y las aledañas a los cursos de agua, las que son vendidas o entregadas en comodato a emprendedores foráneos.

La imaginación se nutre de los significados que avanzan por las rutas carreteras, trayendo consigo una cosmovisión centralina instalada en un nuevo escenario. En Malalhue, el club de rodeo, las carreras a la chilena, los dos grupos folclóricos, se unen a una civilidad constituida por el cuerpo de bomberos, el centro cultural, la iglesia católica y el gimnasio. Amparada la población en una cosmovisión de los llanos no tarda en encontrar dificultades para adaptarse a un medio dominado por las aguas. Las inundaciones, la lluvia permanente, las necesidades de aprovisionamiento, les obliga a depender del control de las aguas y, por lo tanto, de la inversión pública.

La identidad del pueblo se constituye a partir de una concepción diferente de las aguas. Las familias usaban el río para lavar la ropa, la lana de la esquila y los colchones. Las artesas se tornaban botes y, mientras hubo agua suficiente, la semana de Malalhue incluía un pequeño corso fluvial. En los recuerdos de las y los residentes, los pozos artificiales adquieren una importancia especial. Son fuente de aprovisionamiento del agua para consumo y para aseo personal y lavado pero también se dejan rodear por el misterio. "Mi abuela Rosa", afirma un profesor malalhuino, "hablaba de cómo los pozos tenían vida y de cómo siempre había una energía". Los pozos construidos por la población son fuente de orgullo y la comunidad los relaciona con el estero de Huillimallín que se dice que los alimenta. El progreso se mide según la mecanización en el uso de las aguas. El pueblo valoró la campaña que se hiciera por dotar a los hogares de bombas para el sacado del agua como hoy lo hace en relación al agua potable rural.

El otro elemento importante en la memoria local son las cunetas. Su papel en la vida comunitaria trasciende su función inicial, esto es, la de acarrear las aguas lluvia. Son marcadores que permiten delimitar territorios e identificar personas y lugares. También son lugar de juego para los niños y niñas y de seguridad para el mundo adulto. La cosmovisión malalhuina, a diferencia de la mapuche, valora las aguas contenidas, aquéllas sobre las que puede ejercer control y dirigir a antojo, y los medios técnicos que le permiten hacerlo. En parte es lo que marca la separación entre ambos mundos.

La población colona de la cuenca adaptó el medio a las demandas de una actividad cuyo destino era extralocal. Para hacerlo recurrió a una lógica reticular por cuyo medio intervino los cursos de agua para el abastecimiento y para las actividades productivas. Los movimientos de las personas en el paisaje lacustre quedan concatenados por un sistema 


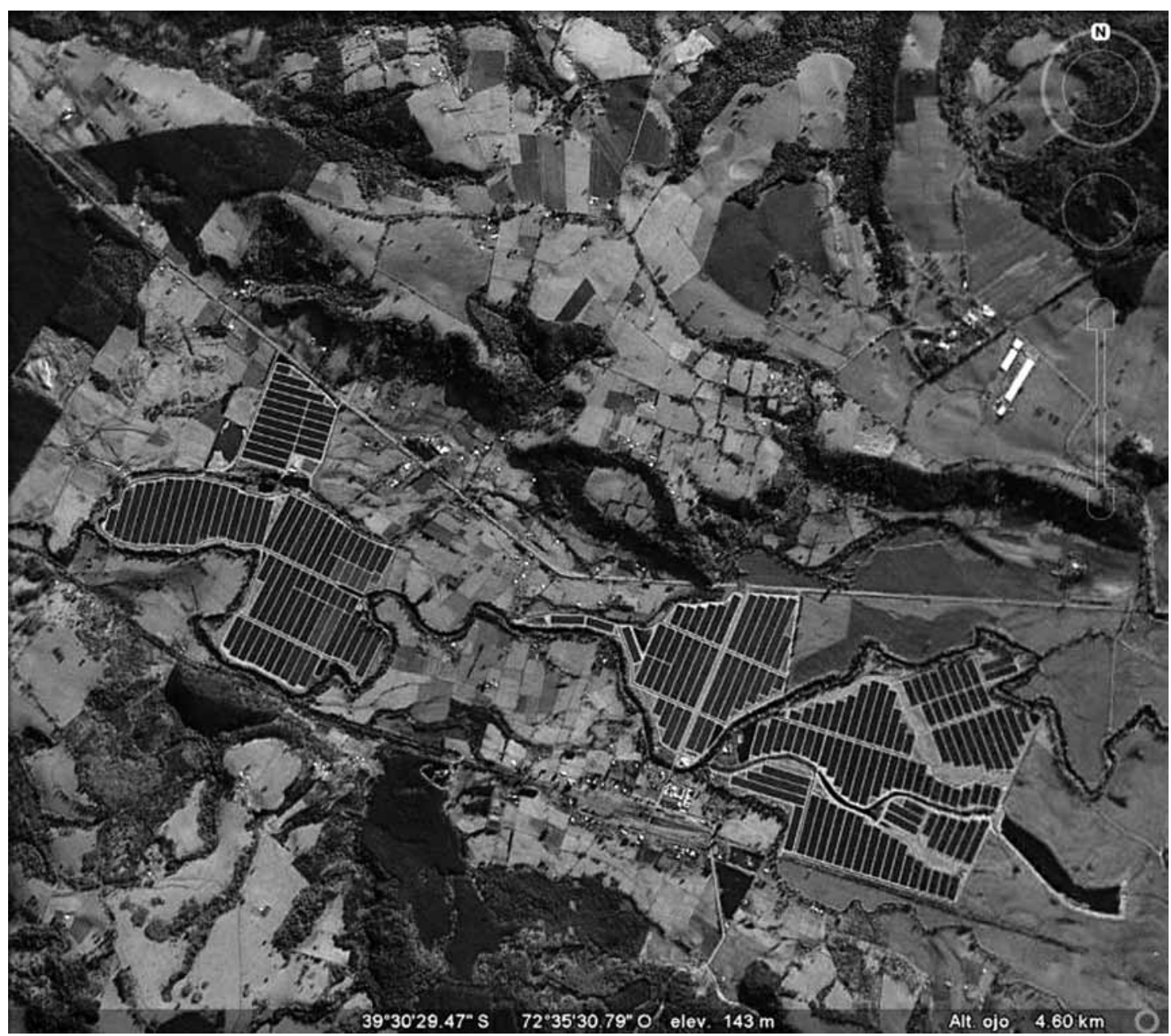

Figura 6. Las camas de cranberries en la comuna de Lanco (adaptado de Google Earth). Cranberries beds in Lanco county (adapted from Google Earth).

ortogonal que les es invisible. Los lagos fueron sometidos a igual régimen a través de la navegación, y los cursos menores fueron reencauzados según las necesidades de la población. La domesticación de las aguas es un velo que constriñe, organiza y dirige la acción de las nuevas poblaciones, manteniendo dos hitos referenciales inescapables: las propiedades y la conectividad entre ellas y con los centros urbanos. El espacio de la cuenca queda circunscrito a un estrecho pasaje en la memoria de los colonos, pasaje que - no obstante- les confiere identidad y sentido.

La yuxtaposición de la dendrita y la retícula plantea un nuevo orden de relaciones $y$, consecuentemente, acomodos, reacomodos e infiltraciones recíprocas de las poblaciones que se ven involucradas. La expansión forestal, el desarrollo de las centrales hidroeléctricas y las plantaciones de arándanos o cranberries (Vaccinium sp.) son parte de las amenazas que, enmarcadas en un acceso más restricto al agua, se ciernen sobre la comunidad.

Las empresas, construyendo diques, piletas y presas, imponen sus estructuras al paisaje encapsulando con ello el curso de las aguas. A modo de ejemplo, la Figura 6 ilustra el emplazamiento de la empresa Cranchile en la comuna de Lanco. En la medida en que los colonos chilenos comienzan a sentirse desprotegidos por la ausencia del Estado en relación a la actividad maderera, agroindustrial y en los usos de las aguas, comienzan a reconocer en sus vecinos mapuche el valor de la otra cultura, lo que lleva a la incorporación progresiva de lo indígena en la vida cultural del pueblo, y a un aprendizaje aún en ciernes de sus enseñanzas. Valoran las 
propiedades de las aguas de las vertientes y de las que afloran desde las rocas y exploran otros usos, alternativos a las plantaciones forestales o a los vertederos de basura.

La influencia de estos procesos cobra vida en Panguipulli. Allí la proclamación del territorio como reserva de la biósfera es indicio de una manera alternativa de acometer el futuro. "No queremos que asfalten los caminos, que lleguen los turistas y expulsen a la gente de la tierra", reclama un vecino de Panguipulli. "Lo que queremos es asegurar la calidad de vida de esta tierra". Y al enunciarlo intenta recoger la tradición indígena local y amalgamarla de un modo diverso al hasta ahora experimentado.

\section{Conclusiones}

Las identidades se anclan en el paisaje y el agua aparece como la matriz natural que moldea la autopercepción y la relación con los otros grupos que habitan los paisajes cordilleranos en el sur de Chile. La modalidad a partir de la que se articulan las identidades locales originarias es de carácter dendrítico, esto es, se constituyen a partir de un haz de relaciones entre múltiples nodos cuyo trasfondo ecológico es de naturaleza hídrica. Este carácter contrasta con el poblamiento chileno que se constituye sobre la base de una retícula vial, fluvial y lacustre, caracterizada por su naturaleza rectilínea y asociada a la búsqueda del control creciente de las aguas.

La relación con las aguas es igualmente discrepante cuando se comparan las poblaciones indígenas y chilenas. Las comunidades mapuche fundan su relación con el mundo hídrico sobre la base de un respeto recíproco y entienden que el comportamiento de las aguas retruca el comportamiento humano. Las poblaciones chilenas, en cambio, procuran imponer sus estructuras al medio hídrico y lo hacen sobre la base del aprisionamiento de los cuerpos de agua. La construcción de diques, piletas, presas, pozos y otros medios de contención ilustran este patrón. Subyacen a este comportamiento ideas del agua como repositorios o lavaderos; por el contrario, en la perspectiva indígena, el agua, junto con su carácter sagrado, es una corriente que lleva energía. El edificio ideacional que corona estas concepciones acerca de las relaciones entre las aguas y los humanos adquiere, en el mundo indígena, un sentido religioso donde el fluir pasa a ser la condición básica de las cosas. Por el contrario, en el mundo chileno, la sacralidad se encapsula en la arquitectura religiosa y el agua se conceptúa de modo jurídico, estableciendo derechos y concesiones que tienden a legitimar toda forma de entrampamiento.

La dicotomía no es lo radical que pudiese aparecer. Las relaciones entre las poblaciones chilena y mapuche se encuentran en un proceso de redefinición. Por mucho tiempo la población chilena miró hacia el norte con la esperanza de cobrar su parte en el proyecto modernizador. La llegada del tren y la Carretera Panamericana fueron alicientes importantes para conservar esta esperanza. La devastación producida por las plantaciones forestales dejó en evidencia que la ruta escogida no era la mejor. Hoy tanto las autoridades locales como las comunidades han emprendido una búsqueda de sentido en la relación con la población mapuche, donde la protección del agua reclama un lugar central.

En el escenario actual se han intensificado los conflictos ambientales derivados tanto de proyectos hidroeléctricos como de actividad forestal y agrícola. El drenaje de las napas, la contaminación industrial y los regímenes de concesión y acuicultura han puesto el agua en el centro de las tensiones regionales. Estos mismos conflictos motivan acciones de resistencia transversal asociadas a la emergencia de nuevos actores colectivos, lo que abre paso a dinámicas cuyo alcance aún es difícil de precisar.

Agradecimientos: Este artículo se basa en el Proyecto Fondecyt F-1090465: "Los Paisajes del Agua: Prácticas Sociales y Sustentabilidad en la cuenca del Río Valdivia”. Se agradece a las comunidades y residentes del lago Neltume, de Malalhue, Milleuco y Panguipulli por su desinteresada colaboración, a nuestros ayudantes Camilo Avendaño y Pablo Rojas y a nuestro colega Christian Henríquez, junto con Alex Utreras y Rodrigo Rehbein por el apoyo en los registros audiovisuales y a Francisca Solari y Alex Utreras por la transcripción de los textos. Se agradece al Dr. Manuel Fuenzalida por su apoyo cartográfico. De modo especial se agradece a quienes revisaron este artículo: sus sugerencias y observaciones fueron especialmente significativas en la organización de lo aquí argumentado. 


\section{Referencias Citadas}

Alarcón, M. 1958. Panguipulli, el Pueblo y la Comuna. Loncoche. Tesis para optar al título de Profesora de Educación Primaria. Universidad Católica de Chile. Escuela Normal Santa Cruz. Loncoche.

Barrera, A. 2000. Identidades, lenguas, ideologías. Una interpretación desde la antropología. En Antropología: Horizontes Interpretativos, editado por C. Lisón, pp. 11-30. Universidad de Granada, Granada.

Bernedo, P. 1997. Panguipulli, Historia de Cuatro Tiempos. Editor Hans Storandt, Santiago.

Camus, P. y M.E. Solari 2008. La invención de la selva austral. Bosques y tierras despejadas en la cuenca del río Valdivia (siglos XVI - XIX). Revista de Geografía Norte Grande 40:5-22.

Connors, W. 1994. Ethno-nationalism. The Quest for Understanding. Princeton University Press, Princeton.

Criado, F. 1999. Del Terreno al Espacio: Planteamientos y Perspectivas para la Arqueología del Paisaje. Grupo de Investigación en Arqueología del Paisaje, Universidad de Santiago de Compostela, Santiago de Compostela.

De Augusta, Fr. F. 1995 [1916]. Diccionario Mapuche-Español. Séneca, Santiago.

De Certeau, M. 1984. The Practice of Everyday Life. Traducido por S. Rendall. University of California Press, Berkeley.

Diario Oficial 1931. Ley núm. 8.721, que crea la comunasubdelegación de Panguipulli, en el departamento de Valdivia, pp. 1893-1899. Santiago.

Díaz, A. 2005 [1907]. Parlamento de Coz Coz. Imprenta Araucaria, Santiago.

Dirección General de Obras Públicas 1932. Camino de Lanco a Panguipulli. Antecedentes Completos para su Construcción. Imprenta Cóndor, Santiago.

Douglas, M. 1988 [1970]. Símbolos Naturales. Exploraciones en Cosmología. Traducido por C. Criado. Madrid, Alianza.

Endesa 2010. Estudio de Impacto Ambiental Central Hidroeléctrica Neltume. 06334-05-06-IIS-EIA-001. Versión 0. Ingendesa, Santiago.

Escobar, A. 1999. El Fin del Salvaje. CEREC, Bogotá.

Foerster, R. 1995. Introducción a la Religiosidad Mapuche. Universitaria, Santiago.

González, I. 2007. La percepción y el trazado del territorio latente. En La Construcción Social del Paisaje, editado por J. Nogué, pp. 163-180. Biblioteca Nueva, Madrid.

Guerra, D., M. Barrientos y S. Ramírez 1999. Las Ñañas. LOM, Santiago.

Hirsch, E. y M. O'Hanlon 1995. The Anthropology of Landscape: Perspectives on Space and Place. Clarendon Press, Oxford.

Ingold, T. 2007. Lines. A Brief History. Routledge, Londres y New York.

Irribarra, C. 1909. Memoria. Protectorado de Indíjenas-Provincia de Valdivia-Año 1908.

Larraín, J. 2003. Los distintos niveles de la identidad cultural. En Revisitando Chile. Identidades, Mitos e Historias, compilado por S. Montecino, pp. 67-73. Cuadernos Bicentenario, Santiago.
Latcham, R. 1924. La Organización Social y las Creencias Religiosas de los Antiguos Araucanos. Publicaciones del Museo de Etnología y Antropología de Chile, Imprenta Cervantes, Santiago.

Latour, B. 1999. Pandora's Hope. Essays on the Reality of Science Studies. Harvard University Press, Cambridge.

Lawrence-Zuñiga, D. 1996. Review of The Anthropology of Landscapes. Editado por E. Hirsch y M. O'Hanlon (1995). American Anthropologist 98:915-916.

Lindsay, K.A., J.M. Ogden y J.R. Rosenberg 2001. Dendritic subunits determined by dendritic morphology. Neural Computation $13: 2465-2476$.

Lipietz, A. 2002. ¿Qué es la Ecología Política? La Gran Transformación del S. XXI. LOM e IEP, Santiago.

Ministerio de Hacienda 1906. Decreto 2498, 10 de junio. Santiago.

Rehren, O. 1908. Memoria de la Inspeccion Jeneral de Colonizacion e Inmigracion. Imprenta y Encuadernacion Universitaria, Santiago.

Rivas, R. 2006. Desarrollo Forestal de Neltume: Estado y Trabajadores (1924-1990). Tesis para optar al título de Profesor de Historia y Geografía, Universidad Austral de Chile, Valdivia.

Sauer, C. 1925. The morphology of landscape. University of California Publications in Geography 2:19-54.

Sellin, E. 1996. A congruence of landscape and the mind. Literary Review 39:492-503.

Skewes, J.C. y M. Silva 2007. Elementos para una comprensión ecológico-cultural de las narraciones míticas acerca de las aguas y los seres del agua en la cosmovisión mapuche huilliche. En Sociedad y Cultura: Reflexiones Transdisciplinarias, editado por C. Rodríguez, R. Browne, C. del Valle y S. Figueroa, pp. 129-138. UACh, UFRO, MECESUP, Valdivia.

Strang, V. 2006. Substantial connections: Water and identity in an English cultural landscape. Worldviews: Environment Culture Religion 10:155-177.

Triviños, E. 1959. Poblaciones Alrededor de Panguipulli. Tesis para optar al título de Profesora de Educación Primaria. Universidad Católica, Facultad de Filosofía y Letras, Normal Santa Cruz.

Tuan, Y-F. 1974. Topophilia: A Study of Environmental Perception, Attitudes and Values. Prentice-Hall, Englewood Cliffs, New Jersey.

Villagrán, C., V. Castro y G. Sánchez 2000. Etnobotánica y percepción del paisaje en Caspana ¿Una cuña atacameña en el Loa Superior? Estudios Atacameños 16:107-170.

Whiteaker, T.L., J. Goodall, D. Maidment y M. Takamatsu 2006. Integrating arc hydro features with a schematic network. Transactions in GIS 10:219-237.

Wilhelm de Moesbach, P.E., W. Meyer, A. Vúletin y E. Suárez 1993. Nuevo Diccionario Mapuche-Español. Nombres Propios Mapuches. Topónimos de Neuquén. Mitologías Patagónicas. Siringa Libros, Buenos Aires.

Zedeno, M.N., D. Austin y R. Stoffle 1997. Landmark and landscape: A contextual approach to the management of American Indian resources. Culture \& Agriculture 19:123-129. 